\title{
Alloy design for intrinsically ductile refractory high-entropy alloys
}

\author{
Saad Sheikh, ${ }^{1}$ Samrand Shafeie, ${ }^{1}$ Qiang Hu, ${ }^{2}$ Johan Ahlström, ${ }^{1}$ Christer Persson, ${ }^{1}$ \\ Jaroslav Veselý, ${ }^{3}$ Jiř́ Zýka, ${ }^{3}$ Uta Klement, ${ }^{1}$ and Sheng Guo ${ }^{1, a)}$ \\ ${ }^{1}$ Department of Materials and Manufacturing Technology, Chalmers University of Technology, \\ Gothenburg 41296, Sweden \\ ${ }^{2}$ Institute of Applied Physics, Jiangxi Academy of Sciences, Nanchang 330029, People's Republic of China \\ ${ }^{3}$ UJP PRAHA a.s., Nad Kamínkou 1345, Prague 15610, Czech Republic
}

(Received 30 September 2016; accepted 18 October 2016; published online 28 October 2016)

Refractory high-entropy alloys (RHEAs), comprising group IV (Ti, Zr, Hf), V (V, Nb, Ta), and VI $(\mathrm{Cr}, \mathrm{Mo}, \mathrm{W})$ refractory elements, can be potentially new generation high-temperature materials. However, most existing RHEAs lack room-temperature ductility, similar to conventional refractory metals and alloys. Here, we propose an alloy design strategy to intrinsically ductilize RHEAs based on the electron theory and more specifically to decrease the number of valence electrons through controlled alloying. A new ductile RHEA, $\mathrm{Hf}_{0.5} \mathrm{Nb}_{0.5} \mathrm{Ta}_{0.5} \mathrm{Ti}_{1.5} \mathrm{Zr}$, was developed as a proof of concept, with a fracture stress of close to $1 \mathrm{GPa}$ and an elongation of near $20 \%$. The findings here will shed light on the development of ductile RHEAs for ultrahigh-temperature applications in aerospace and power-generation industries. Published by AIP Publishing.

[http://dx.doi.org/10.1063/1.4966659]

\section{INTRODUCTION}

The quest for ultrahigh temperature structural materials superior to nickel-based superalloys is essentially driven by the need to improve the efficiency of aerospace and powergeneration gas-turbine engines, by operating at higher temperatures. The efficiency and performance of jet engines are strongly dependent on the highest temperature in the engine, i.e., the inlet temperature of the high pressure turbine blades. Today's engines expose nickel-based superalloys to temperatures approaching $1150{ }^{\circ} \mathrm{C}$, close to $90 \%$ of their melting points. ${ }^{1}$ Although the use of complex cooling systems and thermal barrier coatings can enable them to exist in the hottest region of a turbine engine with temperatures approaching $1500^{\circ} \mathrm{C}$, the efficiency gained from operating at higher temperatures is greatly reduced. New ultrahigh temperature materials, therefore, must be developed that can operate at higher temperatures $\left(>1300^{\circ} \mathrm{C}\right)$ without the need for cooling. ${ }^{1,2}$

Conventional alloys, including nickel-based superalloys, are based on one or sometimes two principal elements, for example, $\mathrm{Fe}$ in steels and $\mathrm{Ti}$ and $\mathrm{Al}$ in TiAl based intermetallics. The recently emerging high-entropy alloys (HEAs), however, provide a novel alloying strategy that significantly expands the scope of the conventional alloy design. ${ }^{3-12}$ HEAs typically consist of at least four principal metallic elements in near-equiatomic ratios and therefore have a higher configuration entropy than that in conventional alloys. Due to their unique features, including high softening resistance at elevated temperatures, the slow diffusion kinetics, and high oxidation resistance, HEAs naturally possess the advantages to be considered as new types of high-temperature alloys. If these unique advantages can be further combined with the

\footnotetext{
a) Author to whom correspondence should be addressed. Electronic mail: sheng.guo@chalmers.se
}

high melting point of refractory elements, i.e., group IV (Ti, Zr, Hf), V (V, Nb, Ta), and VI (Cr, Mo, W) refractory elements, the idea of refractory HEAs (RHEAs) ${ }^{13-16}$ would be a highly interesting alloying concept, aiming at hightemperature applications. However, the current bottleneck for utilizing RHEAs as structural materials is their general room temperature brittleness. ${ }^{17-21}$ Interestingly, among the reported RHEAs, there exist two alloys that possess tensile ductility at room temperature: equiatomic quaternary $\mathrm{HfNbTiZr}^{22}$ and equiatomic quinary HfNbTaTiZr. ${ }^{23}$ The mechanism behind the ductility of HfNbTiZr and HfNbTaTiZr, in a sharp contrast to other brittle RHEAs, however, remains unknown. Revealing the ductilizing mechanism for RHEAs from the alloy design perspective, aiming for the development of more ductile RHEAs with adjustable compositions (for example, using lighter elements to reduce the density), constitutes the topic of the current work.

Particularly, in this work, we will tune the ductility of RHEAs utilizing the electron theory, with the objective to achieve the intrinsic ductility. The reasoning behind our alloy design strategy is based on a very recent theoretical work in intrinsically ductilizing bcc refractory alloys. ${ }^{24} \mathrm{An}$ important theoretical ductility criterion for group $\mathrm{V}(\mathrm{V}, \mathrm{Nb}$, Ta)- and VI metal (Cr, Mo, W)-based bcc refractory alloys is the mechanical failure mode of their perfect crystals under tension along the weakest direction [100]. For example, pure group $\mathrm{V}$ elements like $\mathrm{V}$ and $\mathrm{Nb}$ fail by shear deformation and they are intrinsically ductile, while pure group VI metals like Mo and $\mathrm{W}$ fail by cleavage and they are deemed intrinsically brittle. Interestingly, first-principles calculations show that alloying pure $\mathrm{Mo} / \mathrm{W}$ with group IV (Ti, $\mathrm{Zr}, \mathrm{Hf}$ ) or group $\mathrm{V}$ transition metals can transform them into intrinsically ductile materials, failing in shear under [100] tension. It is intriguing to know whether the same principle can be extended from binary bcc refractory alloys to multicomponent bcc RHEAs. If it does, this means elements from group 
$\mathrm{V}$ or group IV, when alloyed with elements from group VI or group $\mathrm{V}$, can lead to intrinsically ductile RHEAs. Interestingly, this scenario seems to be supported by the two existing ductile RHEAs: $\mathrm{HfNbTiZr}^{22}$ and HfNbTaTiZr, ${ }^{23}$ where in the quaternary alloys, the group $\mathrm{V}$ element $\mathrm{Nb}$ is alloyed with group IV elements $\mathrm{Ti}, \mathrm{Zr}$, and $\mathrm{Hf}$, while in the quinary alloys, group $\mathrm{V}$ elements $\mathrm{Nb}$ and $\mathrm{Ta}$ are alloyed with group IV elements $\mathrm{Ti}, \mathrm{Zr}$, and $\mathrm{Hf}$. On the other hand, if group $\mathrm{V}$ elements $\mathrm{Nb}$ and $\mathrm{Ta}$ are alloyed with group $\mathrm{V}$ and group VI elements V, Mo and $\mathrm{W}$ with more valence electrons, the formed alloys MoNbTaW and MoNbTaVW are brittle. ${ }^{17,19}$ From both the theoretical analysis and available experimental results, decreasing the average valence electron numbers, or valence electron concentrations (VEC), ${ }^{24,25}$ has been proven effective in ductilizing refractory alloys. Along this line of thinking, we developed a new ductile RHEA in this work, further validating the alloy design strategy of intrinsically ductile RHEAs using the electron theory.

\section{EXPERIMENTAL}

A new RHEA with the nominal composition, $\mathrm{Hf}_{0.5} \mathrm{Nb}_{0.5} \mathrm{Ta}_{0.5} \mathrm{Ti}_{1.5} \mathrm{Zr}$, was prepared, a modified composition to existing ductile RHEAs, HfNbTiZr and HfNbTaTiZr, keeping its VEC low and comparable to that of these known ductile RHEAs. The alloy preparation was carried out using high purity (>99.9\%) elemental materials by arc melting on a water-cooled copper plate in a Ti-gettered Ar atmosphere. The arc-melted ingot was flipped and re-melted at least five times to ensure thorough mixing and chemical homogeneity. The ingot has the dimension of about $60 \mathrm{~mm}$ (length) $\times$ $20 \mathrm{~mm}$ (width) $\times 10 \mathrm{~mm}$ (thickness). The microstructure of the as-cast sample was studied on polished and chemically etched specimen using a LEO Gemini 1550 scanning electron microscope (SEM). The etchant used to reveal the microstructure was a mixture of $1.5 \mathrm{ml}$ nitric acid, $5 \mathrm{ml}$ hydrofluoric acid, and $45 \mathrm{ml}$ water, for approximately $10 \mathrm{~s}$. The crystal structure of the alloy was examined by Bruker AXS D8 advance X-ray diffraction (XRD) system using Cr$\mathrm{K} \alpha$ radiation. Vickers hardness was measured on the polished surface applying $1 \mathrm{~kg}$ load for $15 \mathrm{~s}$. The density of the alloy was measured following the Archimedes' principle. A rectangular dog-bone-shaped tensile specimen with a gauge length of $12.5 \mathrm{~mm}$, a width of $3.2 \mathrm{~mm}$, and a thickness of $2 \mathrm{~mm}$ was machined from the ingot by electrical discharge machining, followed by surface polishing. Tensile testing was carried out using an Instron $5500 \mathrm{R}$ electro-mechanic tensile tester, with a strain rate of $10^{-3} \mathrm{~s}^{-1}$.

\section{RESULTS AND DISCUSSION}

Figure 1 shows the backscatter electron image of the microstructure of the as-cast $\mathrm{Hf}_{0.5} \mathrm{Nb}_{0.5} \mathrm{Ta}_{0.5} \mathrm{Ti}_{1.5} \mathrm{Zr}$ under SEM. A dendritic structure can be clearly observed. The XRD pattern, shown in the inset in Fig. 1, indicates that a singlephase bcc structure was achieved. All constituent elements have a bcc crystal structure just below their melting temperatures. Alloying of $\mathrm{Nb}$ with $\mathrm{Ta}$ leads to a continuous bcc solid solution in the entire compositional range. ${ }^{26}$ All other pairs of constituent elements (Hf-Nb, Hf-Ta, Hf-Ti, Hf-Zr, Nb-Ti, Nb-

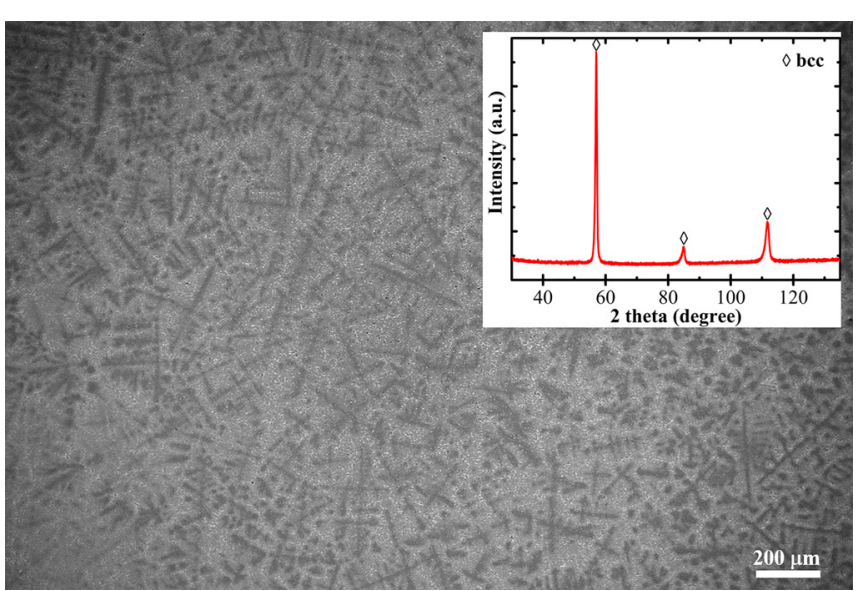

FIG. 1. Microstructure of as-cast $\mathrm{Hf}_{0.5} \mathrm{Nb}_{0.5} \mathrm{Ta}_{0.5} \mathrm{Ti}_{1.5} \mathrm{Zr}$ alloy with typical dendritic morphology. The inset shows the XRD pattern.

$\mathrm{Zr}$, Ta-Ti, Ta-Zr, and Ti-Zr) also form continuous bcc solid solutions in the entire composition range just below solidus temperatures but can transform fully or partially to hcp solid solutions at low temperatures. ${ }^{26}$ The bcc solid solution that was achieved in the as-cast $\mathrm{Hf}_{0.5} \mathrm{Nb}_{0.5} \mathrm{Ta}_{0.5} \mathrm{Ti}_{1.5} \mathrm{Zr}$ alloy is then stabilized by the high configuration entropy and therefore the low Gibbs free energy, while the formation of hcp phase is kinetically restricted, possibly due to the sluggish diffusion in the alloy. ${ }^{27}$ A note can be added here on the segregation in the dendritic structure. Segregation is commonly seen in directly cast HEAs, and is also seen here for the new RHEA. From the XRD result, the segregation does not cause any new phase with a different crystal structure and noticeably different lattice constants. The material can therefore still be regarded as a single-phase bcc structure. On the one hand, since in this work we are mainly addressing the intrinsic ductility of REHAs, the effect of microstructure including the elemental segregation on the ductility is not given too much focus. On the other hand, we are already in the process of using thermomechanical treatments to modify the microstructure via recrystallization. The segregation is no longer an issue in the recrystallized RHEA.

The Vickers hardness of the as-cast $\mathrm{Hf}_{0.5} \mathrm{Nb}_{0.5} \mathrm{Ta}_{0.5}$ $\mathrm{Ti}_{1.5} \mathrm{Zr}$ alloy is $301 \mathrm{HV}$. Figure 2 shows the room

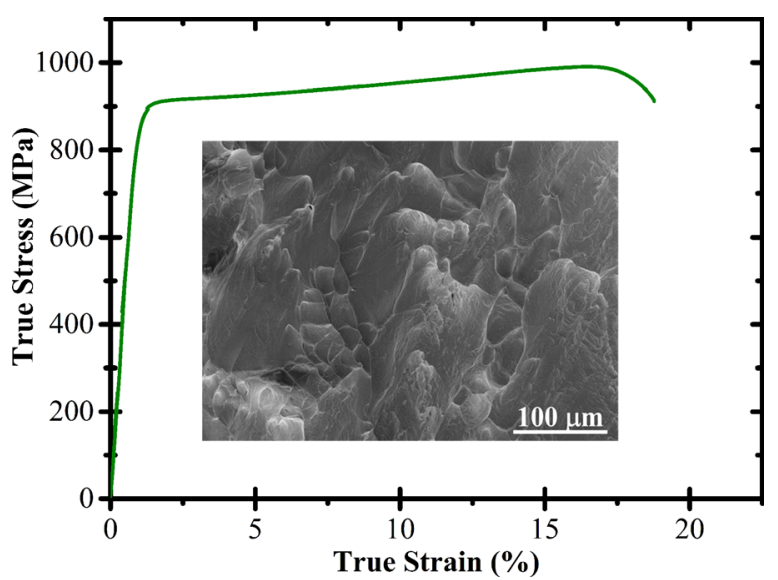

FIG. 2. True tensile stress-strain curve for the as-cast $\mathrm{Hf}_{0.5} \mathrm{Nb}_{0.5} \mathrm{Ta}_{0.5} \mathrm{Ti}_{1.5} \mathrm{Zr}$. The inset shows the microstructure at the fractured surface. 
TABLE I. Refractory HEAs and their VEC, $\delta$, and $\Delta \mathrm{H}_{\text {mix }}$.

\begin{tabular}{lcccc}
\hline \hline Alloy system & VEC & $\delta \times 100$ & $\Delta \mathrm{H}_{\text {mix }}(\mathrm{kJ} / \mathrm{mol})$ & References \\
\hline HfNbTiZr & 4.25 & 4.86 & 2.50 & 22 \\
Hf $_{0.5} \mathrm{Nb}_{0.5} \mathrm{Ta}_{0.5} \mathrm{Ti}_{1.5} \mathrm{Zr}$ & 4.25 & 4.78 & 1.87 & This work \\
HfNbTaTiZr & 4.4 & 4.98 & 2.72 & 23 \\
HfMoTaTiZr & 4.6 & 6.08 & -1.92 & 20 \\
HfMoNbTaTiZr & 4.67 & 5.78 & -0.89 & 20 \\
HfMoNbTiZr & 4.6 & 6.09 & -1.6 & 18 \\
MoNbTaVW & 5.4 & 3.15 & -4.64 & 17 and 19 \\
MoNbTaW & 5.5 & 2.32 & -6.50 & 17 and 19 \\
MoNbTaV & 5.25 & 3.47 & -3.25 & 21 \\
\hline \hline
\end{tabular}

temperature true stress-strain curve for the as-cast $\mathrm{Hf}_{0.5} \mathrm{Nb}_{0.5} \mathrm{Ta}_{0.5} \mathrm{Ti}_{1.5} \mathrm{Zr}$ alloy. A yield stress of $903 \mathrm{MPa}$, an ultimate tensile stress (UTS) of $990 \mathrm{MPa}$, and an elongation to fracture of $18.8 \%$ were achieved, showing a combination of high strength and high ductility. The ductility can be further evidenced from the dimples observed at fractured surfaces, shown in the inset of Fig. 2. The mechanical properties of the as-cast $\mathrm{Hf}_{0.5} \mathrm{Nb}_{0.5} \mathrm{Ta}_{0.5} \mathrm{Ti}_{1.5} \mathrm{Zr}$ alloy are even slightly better than those of existing ductile HfNbTiZr (cast and homogenized) and HfNbTaTiZr (as-cast) RHEAs, where the yield stress, UTS, and elongation are $879 \mathrm{MPa}, 969 \mathrm{MPa}$, and $14.9 \%,{ }^{22}$ and $800-840 \mathrm{MPa}, 850-890 \mathrm{MPa}$, and $6 \%-9 \%,{ }^{23}$ respectively.

Thus, a new ductile RHEA, $\mathrm{Hf}_{0.5} \mathrm{Nb}_{0.5} \mathrm{Ta}_{0.5} \mathrm{Ti}_{1.5} \mathrm{Zr}$, has been designed, based on our intention to develop intrinsically ductile RHEAs following the electron theory. ${ }^{24}$ Table I lists nine different RHEAs containing elements from groups IV, $\mathrm{V}$, and VI, and their corresponding VEC. In all these nine RHEAs, only single-phase bcc solid solutions are formed. Among them, three are ductile (with $>5 \%$ tensile elongation), while six are brittle. Seen from Fig. 3, all ductile RHEAs have a VEC $\leq 4.4$, while all brittle alloys have a $\mathrm{VEC} \geq 4.6$. With a database of nine alloys, it is probably not convincing yet to conclude that there exists a threshold VEC of $\sim 4.5$ below which intrinsic ductility can be achieved in RHEAs, or to accurately predict whether an RHEA with a VEC of 4.5 would be ductile or brittle. However, decreasing VEC in

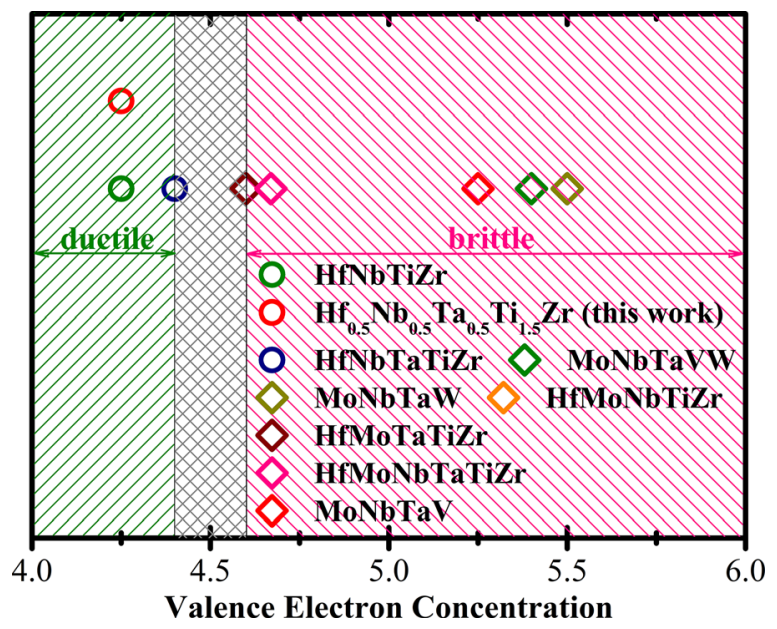

FIG. 3. Separation of ductile and brittle RHEAs by the valence electron concentration.
RHEAs by controlled alloying has indeed been proved effective in ductilizing RHEAs. According to Qi and Chrzan, ${ }^{24}$ the intrinsic brittle to intrinsic ductile transition is determined by the transition of the elastic instability mode from tensile to shear failure, and the intrinsic ductility of bcc refractory alloys depends on whether shear instability occurs before the ideal tensile stress is reached. Tensile strain alters the band structures of these alloys and changes the position of the Fermi level. Alloying additions can shift the Fermi level and can therefore tune the critical strain for the shear instability and the corresponding intrinsic failure mode. More specifically, decreasing the number of valence electrons shifts the Fermi level down relative to the band structure, so less strain is required and the shear instability occurs earlier. From the electronic structure perspective, the shear instability can also be understood from the concept of Jahn-Teller distortion, ${ }^{24}$ which lowers the total energy of the alloy by splitting the degenerate energy levels of symmetry related and partially occupied orbitals near the Fermi level. Specifically, shifting the band structure by removing electrons, so decreasing the number of valance electrons, can increase the density of states (DOS) near the Fermi level and therefore increase the driving force for the Jahn-Teller distortion. DOS peaks just below and above the Fermi level would shift further away from the Fermi level to decrease energies, after the Jahn-Teller distortion. On a different note, Chan discussed the role of $\mathrm{s}+\mathrm{d}$ electrons (they are valence electrons for transition metals) on ductilizing $\mathrm{Nb}$-based alloys from a different perspective other than shear instability. ${ }^{28}$ His approach was based on calculating the surface energy and the Peierls-Nabarro $(\mathrm{P}-\mathrm{N})$ barrier energy as a function of alloy compositions. The surface energy, which is insensitive to alloy additions, was regarded as a measure of the resistance to cleavage fracture, while the $\mathrm{P}-\mathrm{N}$ barrier energy, which is sensitive to alloy additions, was a measure of the dislocation mobility. Chan claimed that decreasing VEC in Nb-alloys, such as by Ti addition, can reduce the $\mathrm{P}-\mathrm{N}$ barrier energy and hence enhance the dislocation mobility and therefore the tensile ductility.

It is proposed here that intrinsically ductile RHEAs can be designed by manipulating VEC through controlled alloying. It has to be emphasized that the strategy is essentially directed to bcc solid solutions, as is the case where Qi and Chrzan exemplified how decreasing VEC can ductilize binary W or Mo alloys. ${ }^{24}$ In the context of RHEAs, this means that the alloy design of ductile RHEAs first has to guarantee the formation of bcc solid solutions and no other phases. A substantial work has been done in guiding the phase selection in HEAs, and it is now known that designing solid solutions forming HEAs can be conveniently helped by the twodimensional $\delta-\Delta \mathrm{H}_{\text {mix }}$ plot, ${ }^{29-32}$ where $\delta$ is the atomic size mismatch among constituent elements and $\Delta \mathrm{H}_{\text {mix }}$ is the averaged mixing enthalpies among different pairs of elements. $\delta$ is defined by $\delta=\sqrt{\sum_{i=1}^{n} c_{i}\left(1-r_{i} / \sum_{j=1}^{n} c_{j} r_{j}\right)^{2}}$, where $n$ is the number of alloying elements, $c_{i}$ is the atomic percentage for the $i$ th element, and $r_{i}$ or $r_{j}$ is the atomic radius for the $i$ th or $j$ th element, respectively), and $\Delta H_{m i x}$ is given by $\Delta H_{m i x}$ $=\sum_{i=1, j>i}^{n} 4 \Delta H_{A B}^{m i x} c_{i} c_{j}$, where $\Delta H_{A B}^{m i x}$ is the enthalpy of mixing for the binary equiatomic $\mathrm{AB}$ alloys. Statistically, it is shown 
that solid solutions can form when $\delta$ is small $(\delta \lesssim 0.066)$, and $\Delta H_{\text {mix }}$ is not significantly negative $\left(\Delta H_{\text {mix }} \gtrsim-11.6 \mathrm{~kJ} / \mathrm{mol}\right){ }^{29}$ Satisfying $\delta<0.066$ and $\Delta H_{\text {mix }}>-11.6 \mathrm{~kJ} / \mathrm{mol}$, however, is necessary but not sufficient conditions to form solid solutions in HEAs, as chances are that intermetallic compounds can still form. ${ }^{29}$ Checking the binary phase diagrams among constituent elements can give some further guidance in designing solid solutions forming HEAs. ${ }^{33}$ For example, for the newly developed $\mathrm{Hf}_{0.5} \mathrm{Nb}_{0.5} \mathrm{Ta}_{0.5} \mathrm{Ti}_{1.5} \mathrm{Zr}$ alloy, there is no intermetallic compound forming in all relevant binary phase diagrams. It is therefore highly likely that as long as the necessary $\delta-$ $\Delta \mathrm{H}_{\text {mix }}$ conditions are satisfied, solid solutions can indeed form, as is the real situation. On the premise that solid solutions are formed, the crystal structure of solid solutions can be tuned by VEC $\left(V E C=\sum_{i}^{n} c_{i}(V E C)_{i}\right.$, where $(V E C)_{i}$ is $V E C$ for the $i$ th element), where a large $\operatorname{VEC}(>8)$ favors the fcc solid solution, while a smaller VEC $(<6.87)$ stabilizes the bcc solid solution. ${ }^{25}$ Finally, to intrinsically ductilize bcc structured RHEAs, VEC needs to be decreased to, for example, $<4.5$, based on what is indicated in Fig. 3. The box delineated by the blue dashed lines in Fig. 4 therefore gives a parametric guidance to design ductile RHEAs from the alloy design perspective: $\delta, \Delta \mathrm{H}_{\mathrm{mix}}$, and VEC can all be calculated from given alloy compositions.

Driven by the needs to increase the efficiency of gasturbine engines, developing novel high-temperature materials with higher working temperatures and ideally reduced densities compared to the currently used Ni-based superalloys is of critical importance. The density of the newly developed RHEA $\mathrm{Hf}_{0.5} \mathrm{Nb}_{0.5} \mathrm{Ta}_{0.5} \mathrm{Ti}_{1.5} \mathrm{Zr}$ was measured to be $8.13 \mathrm{~g} / \mathrm{cm}^{3}$, which is comparable to those of current Ni-based superalloys, and also lower than those of previously reported RHEAs, such as MoNbTaVW (12.36 g/cm $\left.{ }^{3}\right),{ }^{17}$ MoNbTaW (13.75 g/ $\left.\mathrm{cm}^{3}\right),{ }^{17}$ HfNbTaTiZr $\left(9.94 \mathrm{~g} / \mathrm{cm}^{3}\right),{ }^{18}$ HfMoTaTiZr $(10.24 \mathrm{~g} /$ $\left.\mathrm{cm}^{3}\right)$, and HfMoNbTaTiZr $\left(9.97 \mathrm{~g} / \mathrm{cm}^{3}\right) .{ }^{20}$ With an estimated (by rule of mixture) melting point of $2055^{\circ} \mathrm{C}$, $\mathrm{Hf}_{0.5} \mathrm{Nb}_{0.5} \mathrm{Ta}_{0.5} \mathrm{Ti}_{1.5} \mathrm{Zr}$ certainly has the potential to compete with Ni-based superalloys, if it also possesses decent high-

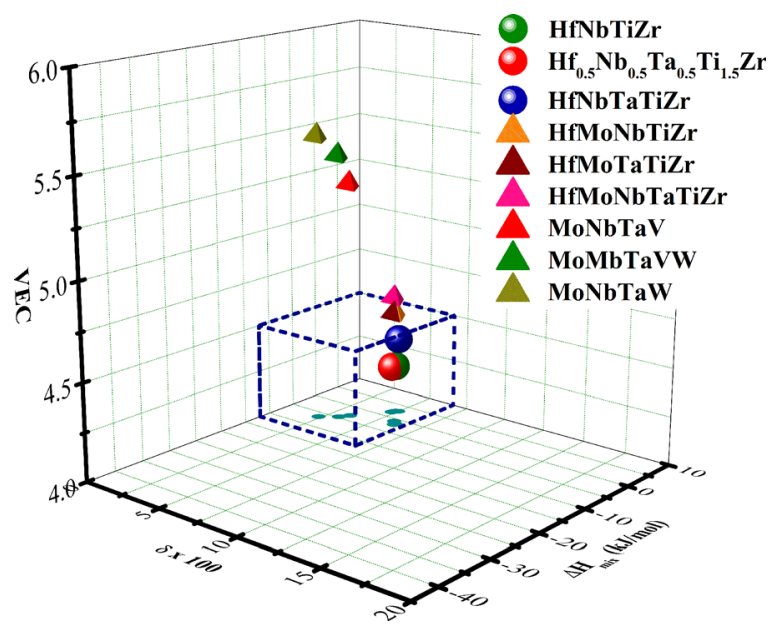

FIG. 4. A plot showing how ductile bcc solid solutions can be predicted by three parameters, atomic size mismatch, $\delta$, averaged mixing enthalpy, $\Delta \mathrm{H}_{\text {mix }}$, and valence electron concentration, VEC, as indicated by the blue dashed box. Parameters for $\delta$ and $\Delta \mathrm{H}_{\text {mix }}$ are also projected onto the $\delta-$ $\Delta \mathrm{H}_{\text {mix }}$ plane, shown as cyan dots. temperature performance including high-temperature strength, resistance to creep deformation, and resistance to corrosion and oxidation. The high-temperature performance of $\mathrm{Hf}_{0.5} \mathrm{Nb}_{0.5} \mathrm{Ta}_{0.5} \mathrm{Ti}_{1.5} \mathrm{Zr}$, and other low-density ductile RHEAs developed following the same alloy design strategy, will be the target for further studies. Nevertheless, solving the room temperature brittleness can be regarded as the first and foremost step in developing RHEAs as new generations of high-temperature materials. Additional optimizations include further reducing the density, and/or increasing the melting point, and enhancing the oxidation and corrosion resistance. In the meanwhile, although as-cast materials already present an attractive combination of high strength and high ductility here, thermomechanical treatments can certainly be used to further improve the mechanical performance.

\section{SUMMARY}

To conclude, here we developed a new ductile RHEA, $\mathrm{Hf}_{0.5} \mathrm{Nb}_{0.5} \mathrm{Ta}_{0.5} \mathrm{Ti}_{1.5} \mathrm{Zr}$, with a density of $8.13 \mathrm{~g} / \mathrm{cm}^{3}$ and $\mathrm{a}$ yield stress of $903 \mathrm{MPa}$, a fracture stress of $990 \mathrm{MPa}$, and an elongation of $18.8 \%$, performing better than previously developed ductile RHEAs. More importantly, we proposed the mechanism and route for ductilizing RHEAs comprising groups IV (Ti, Zr, Hf), V (V, Nb, Ta) and VI (Cr, Mo, W) refractory elements, using the electron theory. Intrinsically ductile RHEAs can be developed by alloying elements from group VI or group $\mathrm{V}$, with elements from group $\mathrm{V}$ or group IV, or in other words by decreasing the number of valence electrons ( $\mathrm{s}+\mathrm{d}$ electrons), in single-phase bcc solid solutions.

\section{ACKNOWLEDGMENTS}

Saad Sheikh and Sheng Guo are grateful for the financial support from Area of Advance Materials Science from Chalmers University of Technology.

\footnotetext{
${ }^{1}$ J. A. Lemberg and R. O. Ritchie, Adv. Mater. 24, 3445 (2012).

${ }^{2}$ J. H. Perepezko, Science 326, 1068 (2009).

${ }^{3}$ B. Gludovatz, A. Hohenwarter, D. Catoor, E. H. Chang, E. P. George, and R. O. Ritchie, Science 345, 1153 (2014).

${ }^{4}$ Z. Li, K. G. Pradeep, Y. Deng, D. Raabe, and C. C. Tasan, Nature 534, 227 (2016).

${ }^{5}$ J. W. Yeh, S. K. Chen, S. J. Lin, J. Y. Gan, T. S. Chin, T. T. Shun, C. H. Tsau, and S. Y. Chang, Adv. Eng. Mater. 6, 299 (2004).

${ }^{6}$ B. Cantor, I. T. H. Chang, P. Knight, and A. J. B. Vincent, Mater. Sci. Eng. A 375-377, 213 (2004).

${ }^{7}$ Y. Zhang, T. T. Zuo, Z. Tang, M. C. Gao, K. A. Dahmen, P. K. Liaw, and Z. P. Lu, Prog. Mater. Sci. 61, 1 (2014).

${ }^{8}$ Z. P. Lu, H. Wang, M. W. Chen, I. Baker, J. W. Yeh, C. T. Liu, and T. G. Nieh, Intermetallics 66, 67 (2015).

${ }^{9}$ M. C. Gao, J.-W. Yeh, P. K. Liaw, and Y. Zhang, High-Entropy Alloys: Fundamentals and Applications (Springer, Cham, Switzerland, 2016).

${ }^{10}$ F. Otto, Y. Yang, H. Bei, and E. P. George, Acta Mater. 61, 2628 (2013).

${ }^{11}$ F. Otto, A. Dlouhý, C. Somsen, H. Bei, G. Eggeler, and E. P. George, Acta Mater. 61, 5743 (2013).

${ }^{12}$ Z. Wu, H. Bei, F. Otto, G. M. Pharr, and E. P. George, Intermetallics 46, 131 (2014).

${ }^{13}$ O. N. Senkov, G. B. Wilks, D. B. Miracle, C. P. Chuang, and P. K. Liaw, Intermetallics 18, 1758 (2010).

${ }^{14}$ Y. Zou, S. Maiti, W. Steurer, and R. Spolenak, Acta Mater. 65, 85 (2014).

${ }^{15}$ S. Maiti and W. Steurer, Acta Mater. 106, 87 (2016).

${ }^{16}$ Y. Zou, H. Ma, and R. Spolenak, Nat. Commun. 6, 7748 (2015).

${ }^{17}$ O. N. Senkov, G. B. Wilks, J. M. Scott, and D. B. Miracle, Intermetallics 19, 698 (2011).
} 
${ }^{18}$ N. N. Guo, L. Wang, L. S. Luo, X. Z. Li, Y. Q. Su, J. J. Guo, and H. Z. Fu, Mater. Des. 81, 87 (2015).

${ }^{19}$ O. N. Senkov, J. M. Scott, S. V. Senkova, D. B. Miracle, and C. F. Woodward, J. Alloys Compd. 509, 6043 (2011).

${ }^{20}$ C. C. Juan, M. H. Tsai, C. W. Tsai, C. M. Lin, W. R. Wang, C. C. Yang, S. K. Chen, S. J. Lin, and J. W. Yeh, Intermetallics 62, 76 (2015).

${ }^{21}$ H. W. Yao, J. W. Qiao, M. C. Gao, J. A. Hawk, S. G. Ma, and H. F. Zhou, Entropy 18, 189 (2016).

${ }^{22}$ Y. D. Wu, Y. H. Cai, T. Wang, J. J. Si, J. Zhu, Y. D. Wang, and X. D. Hui, Mater. Lett. 130, 277 (2014).

${ }^{23}$ G. Dirras, L. Lilensten, P. Djemia, M. Laurent-Brocq, D. Tingaud, J. P. Couzinie, L. Perriere, T. Chauveau, and I. Guillot, Mater. Sci. Eng. A 654, 30 (2016).
${ }^{24}$ L. Qi and D. C. Chrzan, Phys. Rev. Lett. 112, 115503 (2014).

${ }^{25}$ S. Guo, C. Ng, J. Lu, and C. T. Liu, J. Appl. Phys. 109, 103505 (2011).

${ }^{26} \mathrm{H}$. Baker and H. Okamoto, ASM Handbook Volume 3: Alloy Phase Diagrams (American Society for Metals, Ohio, 1992).

${ }^{27}$ K. Y. Tsai, M. H. Tsai, and J. W. Yeh, Acta Mater. 61, 4887 (2013).

${ }^{28}$ K. S. Chan, Metall. Mater. Trans. A 32, 2475 (2001).

${ }^{29}$ S. Guo, Q. Hu, C. Ng, and C. T. Liu, Intermetallics 41, 96 (2013).

${ }^{30}$ S. Guo and C. T. Liu, Prog. Nat. Sci.: Mater. Int. 21, 433 (2011).

${ }^{31}$ Y. Zhang, Y. J. Zhou, J. P. Lin, G. L. Chen, and P. K. Liaw, Adv. Eng. Mater. 10, 534 (2008)

${ }^{32}$ S. Guo, Mater. Sci. Technol. 31, $1223(2015)$.

${ }^{33}$ M. C. Gao and D. E. Alman, Entropy 15, 4504 (2013). 